José Geraldo Alberto B. Poker

Doutorando em Sociologia pela FFLCH - USP.

\title{
A Utopia em Processo de Experimentação
}

Muito se fala sobre Reforma Agrária no Brasil ultimamente. E não é para menos. De um assunto restrito a círculos de acadêmicos ou militantes de esquerda, a questão da terra tornou-se tema de novela na televisão, invadiu as conversas nas ruas e tem espaço garantido diariamente na maioria dos grandes jornais do país. Esta aparente mobilização em torno do tema, porém, nada tem de gratuita.

A atenção dedicada ao problema da concentração da propriedade da terra proveniente da histórica estrutura fundiária brasileira ${ }^{1}$ e das práticas de modernização "conservadora" da agricultura adotadas desde $1950^{2}$, cujas conseqüências têm sido respectivamente a expulsão/expropriação da terra e a inviabilização econô- mica da pequena produção no campo, com certeza não foi motivada pelo aparecimento de sentimentos de compaixão ou ímpetos de solidariedade do restante da sociedade para com a imensa massa de pobres vítimas da exclusão do acesso à terra. O sociólogo Herbert de Souza, o popular Betinho, coordenador da campanha "Ação da Cidadania contra a Fome e a Miséria", bem que tentou sensibilizar a opinião pública para a ligação entre a pobreza e a terra no Brasil, mas não teve muito sucesso. Ao contrário, a recente explosão do tema Reforma Agrária em ambientes que vão desde as conversas informais até o gabinete presidencial, é uma conquista da mais nova estratégia de luta levada avante pelo Movimento dos Trabalhadores Sem Terra (MST).
Não que ao longo dos já 10 anos de sua existência o MST não tenha conseguido chamar a atenção da imprensa, ou permanecesse totalmente incógnito na opinião pública e ignorado nos círculos do poder. Durante esse período, tanto a grande imprensa, como os pequenos jornais e rádios regionais, procuraram noticiar aquilo que os repórteres e a polícia chamam de invasões de terra (ocupações, na linguagem do movimento e de seus simpatizantes) organizadas pelo MST.

Nascido mais ou menos oficialmente nos primeiros anos da década de 1980 e fundado por colonos integrantes de acampamentos articulados sob a mediação da Comissão Pastoral da Terra (CPT) no sul do país, o MST estendeu-se, incendiando os confli- 
tos de terra no Brasil por causa da maneira ágil e inusitada com que engaja participantes, mobilizando-os para práticas sociais pouco convencionais.

Diferentemente de outros movimentos semelhantes existentes em nossa história, que buscavam primeiro as vias institucionais e somente depois do fracasso delas decidiam recorrer ou não à transgressão como forma de reivindicação, o MST descrê por antecipação na vontade dos órgãos públicos em interferir por si mesmos na estrutura fundiária. Por causa disso, escolhe o caminho mais curto para forçar o Estado a intervir e obrigá-lo a apresentar uma solução. Geralmente agrupados em centenas de famílias, ocupam áreas públicas ou privadas consideradas improdutivas, colocando o Estado e seus representantes num impasse radical: reprimir ou ceder. Caso reprima os "invasores", ainda que respaldado em decisões judiciais, o Estado se arrisca a tornar-se o responsável por massacres, como aconteceu em agosto de 95 na Fazenda Santa Elina, no município de Corumbiara - MS, onde morreram 12 pessoas, entre os quais 10 camponeses assassinados pela polícia local, que fora cumprir uma ordem de despejo assinada pelo juiz da Comarca. Fato semelhante aconteceu em Eldorado
Se resolve ceder, o Estado desagrada fazendeiros e seus simpatizantes, comprometendo a credibilidade de vereadores, Prefeitos, Governadores, deputados, senadores, secretários, ministros e Presidente junto àqueles que muitas vezes lhes financiaram o acesso ao poder político nas campanhas eleitorais.

Organizando ocupações freqüentes em diversos lugares do território nacional, inclusive nos estados do Norte e Nordeste, o MST consegue manter presente no cotidiano brasileiro pelo menos um pequeno espaço para divulgação do problema da terra, através da ajuda, ainda que involuntária, dos meios de comunicação.

Por outro lado, devido talvez em parte à radicalidade imprimida à forma de luta, se o MST tem conquistado espaço garantido na imprensa para a sua causa, isso não significa de modo algum que tenha ganho a simpatia da opinião pública enquanto movimento. A própria imprensa, gratuitamente ou por ocasião de alguma ocupação, publica explícita ou implicitamente análises com o claro objetivo de questionar a legitimidade e desqualificar a forma de luta adotada. São comuns noticias envolvendo denúncias a respeito de supostas ligações clandestinas do MST. Houve um tempo em que a moda era enfatizar a presença infiltrada de líderes vindos de Cuba, depois buscou-se associar o MST com a Central Única dos Trabalhadores
(CUT), que financiaria suas atividades. Por último, os jornais e a televisão noticiaram que o serviço de inteligência do Exército suspeitava que os militantes do Movimento estavam sendo treinados por guerrilheiros do grupo terrorista peruano Sendero Luminoso, que seria o responsável ainda pela organização das ocupações mais recentes.

Colunistas de jornais e comentaristas de televisão, quando abordam alguma ação do MST, costumam discretamente sugerir aos leitores e espectadores uma forma de leitura das ocupações, que poderia ser traduzida da seguinte forma: o movimento dos sem terra resume-se em seus líderes, com grande capacidade de iludir pessoas simples. De fato o problema da pobreza decorrente da falta de terra não seria tão grave assim. Em alguns barracos de acampamento existem até carros e televisão. Por isso mesmo é possível acreditar que sejam pessoas manipuladas. Mais ainda, há sempre a ênfase de que as ocupações (invasões) não seriam o procedimento mais adequado para resolver o problema alegado. É necessário que se respeite o estado de direito, sobretudo o direito à propriedade, caso contrário coloca-se em risco a frágil democracia brasileira.

Interpretações como esta, que se sustentam na tese de que o movimento é na verdade o resultado da ação de seus líderes, não se constituem num monopólio do chamado jornalismo oficial. 
Intelectuais da academia partilham de igual concepção, justificando tal posicionamento ancorados em paradigmas teóricos que aparentemente respaldam conclusões dessa natureza.

De um lado, intelectuais localizados mais à "esquerda", acreditam ser o MST o símbolo da aplicação bem sucedida dos preceitos de mobilização da massa a partir da direção estabelecida pelo partido e conduzida pelo intelectual orgânico, tudo isso sintetizado na expressão "conscientização”.

Do lado oposto, interpretações mais “à direita”, por assim dizer, tendem a enxergar o movimento de forma semelhante, apontando para o risco que representa a relativa facilidade com que um grupo de pessoas consegue envolver e influenciar uma multidão de muitas outras, levando-as a agir conforme motivos e razões que por si mesmas jamais encontrariam.

Enfim, por mais que o MST continue organizando ocupações e radicalizando os conflitos de terra, na mesma proporção parece caminhar a insistência da imprensa e da ciência em reduzi-lo à expressão de questões sociais não esclarecidas, produto da ação conscientizadora ou manipuladora de seus líderes, ou simplesmente como caso de polícia.

No entanto, por mais que se esforcem, estas teorias sobre o MST não conseguem compreen- dê-lo em sua real complexidade. $\mathrm{O}$ mérito ou o perigo contidos nas ocupações de maneira alguma podem ser associados apenas a uma das formas assumidas da luta pelo acesso ou conquista de um pedaço de terra. Tampouco forçar o Estado a executar uma reforma agrária pode ser considerado como o horizonte verdadeiro da missão autoatribuída pelo Movimento, que não esconde que sua tarefa estará concluída somente com a transformação da sociedade. E talvez até por acharem ser esta uma meta para além de sua capacidade, simpatizantes e opositores preferem não levar a sério tais devaneios e considerar o Movimento por aquilo que ele menos quer ser: algo passageiro, que tende a desaparecer tão logo se resolva o problema objetivo que lhe deu origem.

Nesse sentido, é complicado, sobretudo ao cientista social, tentar enquadrar o Movimento a partir dos paradigmas teóricos usuais na análise de fatos como esse. Sua complexidade necessariamente exige um olhar multiangular, sem o qual torna-se difícil perceber onde se encontra de fato a diferença entre o MST e os movimentos sociais de luta pela terra que o precederam. Não se está diante, portanto, tão somente de mais um movimento entre tantos que já existiram, que também a seu modo pretendiam influenciar para uma determinada transformação da realidade, ainda que localizada.
Herdeiro da experiência histórica acumulada pelas diferentes tentativas de resistência dos subalternos frente às práticas de dominação, o Movimento dos Sem Terra sintetiza uma diferente solução ao dilema clássico do marxismo a respeito da formação e reprodução do sujeito histórico. Olhando bem de perto, pode-se perceber que o MST parece ter encontrado uma chave para o enigma que tanto tem perturbado a chamada "esquerda" nestes anos "pós-queda do muro": uma resposta para a questão da passagem da situação de classe para a consciência de classe. Junto com isso, desenvolveram-se alternativas de intervenção e atuação que viabilizam práticas concretas de transformação e credenciam o MST a vir a ser um possível materializador moderno de antigas utopias.

Há instantes aludiu-se rapidamente ao fato de o Movimento impressionar uns e assustar outros com a rapidez e eficiência de mobilizar a "massa”, algo que nem contando com os recursos da mídia os partidos políticos, principalmente da "esquerda", tem conseguido fazer.

Da mesma forma, há instantes, mencionou-se de passagem que o MST havia nascido no interior de movimentos mediados pela Comissão Pastoral da Terra (CPT). Criada oficialmente pela Confederação Nacional dos Bispos do Brasil (CNBB) em 1974, a CPT tinha por objetivo "assesso- 
rar, interligar e dinamizar"3 as lutas camponesas existentes, colocando a estrutura material e espiritual da Igreja Católica a seu serviço. Mas não era só isso. Amparados na Teologia da Libertação, os agentes católicos vinculados à CPT ofereciam mais do que "apoio" às lutas camponesas. Usando o espaço aberto pelas Comunidades Eclesiais de Base, exerciam eles também um trabalho de "conscientização" junto à população da periferia das pequenas cidades através da promoção de questionamentos, reflexões e discussões acerca da situação de pobreza e abandono, propiciando assim que grupos de pessoas pudessem conhecer não somente as causas da sua situação, mas sobretudo a forma como ela poderia ser modificada, através da ação coletiva, da formação ou engajamento nos movimentos populares.

Existem vários estudos sobre a influência decisiva que as CEBs e os movimentos populares originados ali exerceram para pressionar a Ditadura Militar a estender os direitos de cidadania, o que forçou os militares a desocuparem o Estado ${ }^{4}$. Não cabe aqui repetir tais estudos, mas enfatizar o fato de que, por intermédio da alquimia entre ingredientes diversos, como elementos religiosos combinados com experiências de vida de pessoas simples, as CEBs conseguiram uma fórmula de “conscientização" de resultados muito superiores à "metodologia” usada pelos partidos de "esquerda” naquele contexto. Tanto que um destes partidos, o PT (Partido dos Trabalhadores), teve em sua base de criação um grande contingente de pessoas ligadas as CEBs.

Comparando a linguagem e a atuação das CEBs com as práticas de "conscientização da massa” realizadas pelos partidos, Frei Betto (1985:35) sintetiza bem a diferença entre uma e outra, inclusive justificando a eficiência da primeira. Diz ele:

"É mais fácil o trabalho de conscientização através da pastoral, do que o trabalho de conscientização através de conceitos marxistas.

Dona Maria vivia se queixando: 'Olha, o jornal é bom, mas esse negócio de hegemonia, correlação de forças e contradições antagônicas não entra na minha cabeça de jeito nenhum!'

Agora, mostre como era a relação de Jesus com os oprimidos de seu tempo, e tudo fica mais claro!"
Isso porque

"A porta da razão do povo brasileiro e latino-americano é o coração. E a chave do coração é a religião. (...) $\mathrm{O}$ povo deste continente é culturalmente cristão. Você pergunta a um camponês latino-americano como ele entende o mundo, a vida, a história. Ele dará uma resposta em categorias religiosas".

Mas não era somente por inserir elementos políticos na fala religiosa que acontecia a "conscientização" no interior das CEBs. Atuando a partir dos preceitos da Educação Popular proposta por Paulo Freire, os agentes pastorais conseguiam fazer da religiosidade o fundamento da racionalidade política, através disso permitindo o desenvolvimento e o fortalecimento de laços de solidariedade e identificação entre os membros de um grupo, o que constitui-se num dos substratos necessários à quaisquer tentativas de mobilização.

A menção a Paulo Freire não é gratuita. Crítico severo das práticas iluministas de "conscientização”, que consistiam em desqualificar a "massa" enquanto subjetividade conceptual e histórica, e que se resumiam, grosso modo, na transferência de modelos de consciência acompanhados dos 
padrões de comportamentos correspondentes a uma determinada clientela ${ }^{5}$, foi Paulo Freire quem explicitou pela primeira vez na pedagogia brasileira a influência das relações de poder no processo pedagógico, componente este responsável pela reprodução do sistema de dominação nas práticas educativas, mas de igual maneira, pela possibilidade de ruptura, possibilitando as ações transformadoras.

Segundo sugere sua teoria, somente poderia haver "conscientização" a partir do momento em que houvesse tempo uma libertação dos sujeitos envolvidos educador/educando - dos papéis socialmente vigentes que legitimam um e excluem outro conforme a posse do conhecimento formal, o único válido, estabelecendo em conseqüência uma ação vertical e unilateral onde o que um ensina o outro deve aprender.

Então, o ato de conscientizar tem início no momento em que pessoas diferentes se encontram e se reconhecem como sujeitos de conhecimentos igualmente diferentes, o que implica necessariamente no reconhecimento do saber cotidiano do educando enquanto conhecimento válido.

Em outras palavras: caso algum educador queira desenvol- ver algum trabalho de conscientização através da educação, deve antes de tudo reconhecer a legitimidade da identidade cultural dos educandos, e não simplesmente tentar substituí-la por outra que considere mais apropriada ao modelo que tende a trazer pronto.

Ou ainda: caso queira interferir no sentido de que alguma coletividade venha a passar da situação de classe para o estágio da consciência de classe, deve o educador primeiramente trabalhar para construir um espaço de sociabilidade que permita o engendramento de outras relações e papéis que venham a libertar as pessoas da posição de subalternidade a que estão submetidas na vida do dia-a-dia. Daí a razão de valorizar suas experiências como ponto de partida para se caminhar por diferentes formas de conhecimento de mundo.

A ação conscientizadora em Paulo Freire, portanto, não se restringe somente à crítica do discurso dominante, não se reduz a uma doutrinação. Implica e requer sobretudo a crítica do cotidiano, naquilo que tem de mais naturalizado: os papéis de ensinar/mandar e aprender/obedecer, que justificam o monopólio da fala de uns em contrapartida ao silêncio de muitos na educação.
Sem que ocorra alguma alteração nestes papéis, nenhum discurso libertador tem significado, por não encontrar correspondência nas relações que acontecem por intermédio dele. Em conformidade com os postulados marxianos $^{6}$, para Paulo Freire não se pode modificar as idéias sem que as práticas materiais que lhes fazem existir como pensamento sejam igualmente modificadas. A construção de um ambiente diferenciado de relações pode servir de base para que um determinado cotidiano seja desnaturalizado, levando-o a perder seu significado, sua força coercitiva como padrão de ação, e enfim desmascarado-o enquanto ideologia.

Não importa muito o conteúdo que motiva e é envolvido pelas relações - se algo baseado na ciência ou religião. $\mathrm{O}$ que importa de fato para que aconteça a conscientização é que tais relações levem as pessoas a redescobrirem a consciência da potencialidade política e da subjetividade histórica: que a realidade do cotidiano pode ser modificada, e o meio para isso encontra-se na ação coletiva. Desse momento em diante, as pessoas podem se apropriar da ciência ou da religião domesticando-as, moldando-as conforme um projeto de transformação que lhes dá uma outra instrumentalidade e um outro signifi-

- $\quad$ Ver FREIRE, 1986 e 1977.

- ${ }^{6}$ A referência feita aqui remete à famosa frase de Marx: "Não é a consciência dos homens que

- determina o seu ser; ao contrário, é o seu ser social que determina a sua consciência”, apud. FER-

- NANDES, 1985, p. 233. 
cado no novo cotidiano a construir.

Compreendendo a "conscientização" nessa perspectiva, fica relativamente fácil entender porque as CEBs vieram a tornar-se o berço e o núcleo de diversos movimentos populares, entre eles os de luta pela terra. Recorrendo novamente a Frei Betto (op.cit:36):

\footnotetext{
"Assim, as CEBs vão criando um espaço de exercício de poder. De um poder democrático que nasce da necessidade, que nasce da base. Com isso vão adquirindo confiança em criar alternativas a esta sociedade e vão sentindo que elas devem ser entrelaçadas com os demais movimentos populares e sindicais."
}

No entanto, apesar da evidência contida nestes argumentos, aplicar as teorias originais de Paulo Freire, ou mesmo a adaptação delas feita pelas CEBs é algo mais difícil do que parece. Nesse sentido, os muitos erros cometidos ao longo dos anos nas experiências de mobilização popular tanto da CPT, como as suas próprias, tem sido outra valiosa fonte de aprendizado para o MST. E é talvez pelo fato de o Movimento conseguir tirar lições dos fracassos e estar disposto a repensar continuamente a prática, que ele opositores.

$\ldots \ldots \ldots \ldots \ldots$
Foi dessa maneira que o MST, além de incorporar e conservar a herança religiosa, também atualizou o que se chama de "metodologia" de ação recebida da CPT. É imprescindível, nos acampamentos e ocupações organizados pelo Movimento, a presença de uma cruz de madeira colocada num ponto estratégico, geralmente ao lado da bandeira do MST. São comuns também imagens de santos em capelas improvisadas, onde se realizam serviços religiosos. Entre outras, a identificação como movimento político-religioso é uma das razões pelas quais o MST, apesar de não estar diretamente ligado à estrutura da Igreja Católica, recebe ainda apoio material e "espiritual" de uma parte considerável de religiosos, padres e bispos. Mais do que isso, o recurso à religião ainda facilita a aproximação, o contato e o engajamento de novos adeptos, além de constituir-se na mediação que sustenta e justifica a legitimidade da estratégia de luta para os seus integrantes.

A alta concentração de elementos de religiosidade no interior do Movimento é algo que a imprensa não mostra, talvez por não dar qualquer importância, mas é o que tem ajudado o MST a relacionar-se de maneira direta e convincente com seu público alvo, como se verá mais adiante, a despeito de toda campanha contrária.
No entanto, se tudo isso parece ter uma importância considerável para se conhecer verdadeiramente o Movimento, há outro aspecto que merece um destaque especial, por ser através dele que o MST pretende agir de modo a interferir na transformação da realidade, que aqui significa esforçar-se para a construção de uma sociedade socialista. Isto seria possível mediante a adoção de práticas coletivistas de trabalho e gestão da terra nos assentamentos conquistados, que viriam a se constituir em modelos alternativos ao individualismo do modo de produção capitalista.

Este é mais um dos projetos herdados não somente da CPT, mas também de toda uma série de experiências da Igreja "progressista" no campo ${ }^{7}$.

Carregado de motivos teológicos, o projeto coletivista da Igreja e defendido pela CPT tinha outros horizontes que não apenas o socialismo. Embora isto jamais tivesse se explicitado, por conta de seu imaginário e da forma como justificava e insistia nas práticas coletivistas, a CPT pretendia, ainda que "inconscientemente", usar o ambiente sob controle dos assentamentos para ali recriar as primeiras comunidades cristãs, o lugar ideal onde o homem poderia se desenvolver e chegar à plenitude da sua existência como fora planejado pelo Criador. Seria este o socialismo 
idealizado.

Não encontrando significação e respaldo cultural entre os assentados, as práticas de coletivização implantadas sob a influência da CPT mostraram-se demasiadamente frágeis, desfalecendo logo aos primeiros conflitos. Por ser uma prática até então desconhecida, mesmo entre os agentes pastorais, o trabalho coletivo (ou comunitário, na linguagem religiosa) implantado não estava suficientemente estruturado e amadurecido como modo de vida, para convencionar e regulamentar novos padrões de relações de produção. Em conseqüência disso, segundo relatos, eram freqüentes os desentendimentos entre assentados causados por problemas na hora da distribuição do produto do trabalho.

Sem conseguir responder satisfatoriamente às necessidades práticas dos assentamentos, a experiência do trabalho coletivo era abandonada, e com isso na maioria das vezes também se deterioravam as relações entre $\mathrm{CPT}$ e assentados. Geralmente, tudo terminava no rompimento de ambos, a maioria dos assentados optando pela gestão familiar da terra, à moda camponesa, e os agentes pastorais culpando o "individualismo", o "egoísmo", a "falta de consciência" e a "introjeção da ideologia dominante" por parte dos assentados como os responsáveis pelo fracasso das tentativas, enquanto que alguns outros se aventuravam por tentativas de combinar práticas coletivas e in- dividuais, formando as Associações, geralmente incentivados por agrônomos.

A resistência manifestada pelos assentados frente à gestão coletiva não se devia à ausência de argumentos convincentes por parte da CPT. A coletivização já naquela época era apresentada como uma forma de assegurar a permanência do assentado na terra, pois sua conquista não significava qualquer alteração nas leis do mercado no qual deveriam se inserir como pequenos produtores. Seria muito mais fácil continuar agindo em grupo, do que buscar meios de capitalização individuais para adquirir as máquinas e a tecnologia necessárias para produzir conforme os padrões do mercado.

Mas ao contrário do que se pensava, a mobilização para a conquista da terra não representou para os grupos, a construção de um referencial de ação que lhes permitisse generalizar e buscar ali a solução para os seus problemas posteriores. Percebeu-se que a racionalidade empregada na luta pela conquista não era a mesma usada para depois de a terra conquistada. Enquanto que na fase de mobilização em geral quase tudo era "comunitário", desde a cozinha até a plantação, tão logo as pessoas recebiam a terra, tendiam a se desviar do projeto coletivo anteriormente estabelecido.

Demorou para que se descobrisse que a experiência de coleti- vização vivida na fase de mobilização era algo apenas tolerado num momento de necessidade, e que deveria desaparecer no exato instante em que a vida voltasse à "normalidade". Por trás das intenções de vida coletiva futura, estava escondido algo muito mais importante e significativo para as pessoas que se arriscavam nos movimentos de luta e que motivava a perseverança diante dos sofrimentos resultantes dela. A maior parte das pessoas tinha um projeto onde conquistar a terra representava adquirir autonomia: conseguir sobreviver sem ter patrão. Diante da maneira como tal desejo de futuro foi elaborado, a idéia da gestão coletiva passava a adquirir um outro significado para os assentados, que viam nessa proposta a recriação da figura do patrão personificado pelo grupo, o que viria a lhes comprometer a realização de seu verdadeiro objetivo.

As pessoas em geral entendiam que somente a gestão familiar/individual da terra - o trabalhar para si - viria a permitir que se conseguisse de fato uma libertação em relação à sua condição anterior de submissão. Nesse caso, como a prática acabou demonstrando, diante da combinação de uma concepção determinada de trabalho, estabelecida culturalmente, com um desejo muito forte de emancipação, quaisquer argumentos, por mais racionais ou religiosos que fossem, não seriam convincentes o suficiente para alterar a consciência das pessoas naquele momento 
e, por conseguinte, provocar a modificação voluntária de uma expectativa de futuro talvez alimentada há anos no passado, onde o presente se constituía apenas numa contingência momentânea, que não deveria ser eternizada.

A CPT retirou-se de cena sem encontrar uma resposta para esta questão. Alguns de seus agentes, depois de participarem de diversas experiências de coletivização, concluíram que o problema estaria na "metodologia”. Segundo eles, ao contrário do que se fazia - a coletivização de tudo de uma só vez - um projeto de coletivização, para que tivesse êxito, deveria sem implementado aos poucos, suavemente, para que os assentados fossem se acostumando, até que alcançasse todos os aspectos da vida. Esta seria a "metodologia” adequada, por meio da qual poder-se-ia convencer os assentados acerca das vantagens da modalidade de trabalho proposta e, ao mesmo tempo, encontrar fórmulas capazes de resolver as desavenças provocadas pela ausência de meios de medir e recompensar o esforço de cada um nos afazeres coletivos.
Foi nesse contexto que o MST assumiu pouco a pouco a mediação e a promoção das mobilizações de luta pela terra no Brasil. Assumiu também o projeto de vida coletiva que deveria ser implantado nos assentamentos, junto com a crença de que, apesar dos fracassos registrados, este poderia ser um objetivo ainda alcançável desde que se encontrasse a "metodologia" adequada para tanto.

Nestes anos que se passaram desde a sua criação, contando com uma competente assessoria de intelectuais da academia, o MST amadureceu e se institucionalizou. Composto por uma estrutura cuja hierarquia compreende as posições de direção, militância, base e massa ${ }^{8}$, o MST apresenta-se como um movimento de massas articulado dentro do movimento sindical, onde as pretensões não se limitam à conquista da terra, tendo extensão política mais ampla. Como já foi afirmado antes, a meta do MST é promover a transformação da sociedade, eliminando as causas da divisão entre ricos e pobres.
Seguindo a linha anteriormente traçada pela CPT, o Movimento pretende ser ao mesmo tempo um movimento de e para camponeses, a medida que a abrangência de sua atuação não se limita a servir aos ideais camponeses de conquista da terra, mas também oferecer uma alternativa de vida em nada parecida com a idealizada pelas pessoas que integram sua massa.

No entanto, apesar de a sua estrutura e atuação lembrar a dos partidos políticos, sobretudo de “esquerda”, o MST não pode ser confundido com eles. O MST pertence a uma "linhagem" de movimentos sociais originada na América Latina nas décadas de 1960 e 1970 e que, segundo EVERS e MARTINS ${ }^{9}$, são compostos por "novos sujeitos" políticos movidos por projetos derivados de uma "identidade cultural". Para ambos os autores, tais movimentos não se destinam a tomar o Estado e a partir daí impor alterações à sociedade. Ao contrário, pretendem ocupar e consolidar um espaço de sociabilidade entre tantos na sociedade civil.
PARTE II

OS MOVIMENTOS SOCIAIS NO CAMPO-ASSENTAMENTOS: CAMINHOSE DESCAMINHOS

\footnotetext{
${ }^{8}$ Segundo o MST, isso remete às seguintes funções: “a) Direção: É o núcleo dirigente responsável pela direção, unidade e condução do movimento de massa. Deve estar a nível local, estadual e nacional. b) Militantes: São os que dão sustentação e organicidade ao movimento de massa. Ou seja, são pessoas mais conscientes, que fazem o vínculo entre os objetivos e decisões que a organização toma com sua ampliação na base e no meio da massa. c) Base: São trabalhadores que se identificam com a organização e se sentem parte dela. d) Massa: São todos os trabalhadores que se mobilizam em torno de objetivos comuns e que dão representatividade ao movimento. É a população atingida pelas mensagens que pode ou não se mobilizar". Isso conforme as instruções da "Cartilha $n^{\circ} .2$ : "Vamos Organizar a Base do MST" - uma publicação do próprio Movimento. Nesse sentido, o trabalho de conscientização, na forma como pretende o MST, deve fazer com que a massa venha a ser transformada em militância. 
A transformação da sociedade, no caso do MST, poderia acontecer de "baixo para cima". Como se estivesse concorrendo com outras instituições no mercado das relações sociais, o projeto de vida oferecido pelo MST poderia conseguir adeptos à medida que se mostrasse viável e eficiente na solução dos problemas materiais e existenciais do mundo pós-moderno. Universalisando seu modo de vida, aí sim poder-se-ia apropriar do Estado, mas apenas para que este servisse de promotor do avanço de relações já praticadas. Daí a institucionalização do Movimento, para que possa permanecer atuante e influente mesmo que porventura a reivindicação que lhe sustenta seja completamente atendida pelo Estado - a promoção de uma ampla reforma agrária que eliminaria a concentração fundiária.

Antes disso, porém, é preciso conquistar assentamentos, pois é neles onde tudo pode começar. Os assentamentos são os lugares ideais que oferecem as condições para a materialização de modos de vida alternativos. Como espaços rurais ainda não plenamente domesticados, a distância das cidades e de outras coletividades favorece o fechamento para o que acontece "fora", obrigando as pessoas a estabelecerem relações e vínculos com os de "dentro". Associado a isso, há também o fato da possibilidade de a experiência de mobilização ter deixado as pessoas mais abertas a experimentar novas situações. Os assentamentos conquistados são ambientes que propiciam a invenção de um novo cotidiano, desde que haja um consenso que permita refazer as regras de convivência que antes eram inconscientemente praticadas.

Mobilizar a massa para ocupar terras parece ser a parte mais fácil na estratégia para alcançar o objetivo proposto. Falando para "camponeses sem terra", o Movimento busca adesão naquilo que supõe constituir-se na identidade de seu público, enquanto reunião de características objetivas e subjetivas. Na concepção do MST (Cartilha no. 2: 5-6), sua massa é definida da seguinte forma:

"Consideramos trabalhadores rurais sem terra todos os companheiros que vivem como parceiros, arrendatários, meeiros, assalariados rurais, ou posseiros e pequenos proprietários até 5 hectares de terra."

"Os Sem Terra são camponeses que, por terem vocação para a roça e não terem terra (...)."

O apelo à identidade cultural é importante para que o Movimento consiga executar a primeira etapa do trabalho de conscientização. Nesse momento, aqueles que se identificam como "camponeses sem terra" na forma acima exposta podem vir a saber o que precisam fazer para conquistar a condição material necessária ao exercício efetivo de sua verdadeira "vocação". Nas palavras do Movimento (op. cit.):
"O Movimento dos Trabalhadores Rurais Sem Terra tem como base a articulação para a luta pela terra, pois não acreditamos que o governo, o Estado ou as classes dominantes vão fazer a reforma agrária por iniciativa própria. Portanto o trabalhador deve se organizar e lutar para conquistar a reforma agrária, sem cair em ilusões de esperar por soluções milagrosas há tantos anos prometidas."

"Em torno do elemento essencial de sua economia, a terra, o Sem Terra se mobiliza, se organiza, faz todas as pressões políticas necessárias até ser assentado."

Outro ingrediente empregado na sedução, mantido da CPT e que de fato estabelece a diferença entre o tipo de abordagem do público realizado pelo MST e pelos partidos, é a chamada "mística". Não se encontram definições muito precisas acerca dela, mas é por seu intermédio que os militantes expressam suas crenças, sentimentos e convicções sobre a causa. São algo rituais e cerimoniais que acontecem antes de quaisquer eventos nas mobilizações, ocupações e assentamentos organizados pelo MST, onde este assume e reforça sua natureza político-religiosa. O recurso à "mistica" nas mobilizações justifica-se assim:

"A mobilização tem que ter volume e tem que atrair. Porque sua finalidade é mostrar a força da união, pressionar na busca de direitos e conseguir outros parceiros. Se for mal organiza- 
da ou mal apresentada, não vai transmitir nossas mensagens nem nossas propostas. Os fatos marcantes ninguém nunca esquece;" (PELOSO, 1994: 7).

Entretanto, a despeito de constituir-se num elemento imprescindível ao processo de mobilização nas ocupações e nos acampamentos, o MST considera que, a partir do momento em que o assentamento acontece, a identidade de "camponês" torna-se o principal obstáculo a ser superado no caminho para a construção do assentamento como ambiente de novas relações sociais. Isso porque, na avaliação do MST,

\footnotetext{
"Quando a terra é conquistada, com o parcelamento da mesma em lotes familiares, o Sem Terra se reintegra, mesmo sem o querer, no processo de organização social dominante: o mercantil capitalista. Assentado em lotes familiares/individuais, passa a ser um produtor simples de mercadorias, utilizando para isso seus próprios meios de produção e o seu precário conhecimento tecnológico. Decidindo sobre o plantio, o consumo e a distribuição dos produtos. Enfim, ele repete a pequena propriedade que sempre sonhou ter." (MST: Cadernos de Formação, no . 20:5)
}

Conquistado o assentamento, tem início então uma outra fase

PARTE II OS MOVIMENTOS SOCIAIS NO CAMPO-ASSENTAMENTOS: CAMINHOSE DESCAMINHOS vimento, que deve ser vivenciada nos grupos de trabalho e nas assembléias, onde a decisão da maioria deve ser cumprida por todos. Não fora portanto um aprendizado meramente teórico, do tipo "como deve ser feito". Ao contrário, os grupos de trabalho e as assembléias são situações de interação onde as pessoas podem provar através de experiências concretas uma outra maneira de se relacionarem.

E esta tem sido a característica da pedagogia desenvolvida pelo MST nestes últimos anos. Antes, a "metodologia" empregada fundamentava-se no princípio de que, do mesmo modo que a identidade cultural fora usada como motivação para uma tomada de "consciência" para o ingresso das pessoas no mundo da racionalidade, poder-se-ia trilhar o caminho inverso. Quer dizer, fazer da consciência a razão que motivaria a construção de uma nova identidade, uma "identidade consciente", daí alterando o cotidiano. Melhor: conforme a concepção cristã, acreditava-se que através da "consciência” poderse-ia operar modificações no modo de vida.

Depois de várias tentativas e erros, o MST e seus assessores aparentemente se voltaram ao caminho inverso, onde não seria uma nova consciência que influenciaria individualmente a mudança de vida, mas ao contrário, o modo de vida é que levaria à nova consciência. $\mathrm{Na}$ interpretação de Paulo Freire (1977:33) nos assen- tamentos isto se resolve da seguinte maneira:

\footnotetext{
"Se a relação que havia antes entre a estrutura dominadora e as formas de perceber a realidade e de atuar nela está desaparecendo, isto não significa que as negatividades da 'cultura do silêncio' hajam perdido sua força condicionante com a instalação do 'asentamiento'. Seu poder inibidor permanece, não como reminiscência inconseqüente, mas como algo concreto, interferindo no quefazer novo que a nova estrutura demanda dos camponeses. Para que se esgote este poder inibidor, é necessário que as novas relações humanas, características da estrutura recém-instaurada e baseadas numa realidade material diferente, sejam capazes de criar um estilo de vida radicalmente oposto ao anterior."
}

A criação de um estilo de vida, no dizer de Paulo Freire, demanda portanto algo mais do que o discurso religioso ou racional. Depende efetivamente da capacidade que o Movimento tiver de promover situações de interação nas quais as pessoas envolvidas possam descobrir diferentes maneiras de se relacionar, e com isso deflagrar em si e por si mesmas um processo de ressocialização, o que permitiria adquirirem uma outra identidade num cotidiano também diferente.

Para tanto o MST tem investido maciçamente no desenvolvimento de uma estratégia pedagógica que permita aproveitar as diversas situações vividas pelas pesta-se do aprendizado da "democracia radical” desejada pelo Mocujas bases devem ter sido preparadas ainda na fase anterior. Tra- 
soas nos ambientes de mobilização, acampamentos (ocupações) ou assentamentos, para propiciar neles um momento de aprendizado do modo de agir coletivo, onde o discurso busca fundamento numa prática que acontece simultaneamente. Inclui-se aí a educação escolar das crianças, que deve se basear na proposição de problemas reais para que as crianças resolvam através da ação em grupo; a educação de adultos, que também deve acontecer da mesma forma; os grupos de trabalho e até mesmo quaisquer cargos de direção ou liderança devem ser ocupados e exercidos coletivamente ${ }^{10}$.

Para além dessas atividades cotidianas, o MST dispõe também de um "laboratório", uma área de terra onde assentados se revezam para aprender como administrar coletivamente um assentamento nos moldes propostos pelo Sistema Cooperativista dos Assentados (SCA), mais uma inovação do Movimento.

Sem meias palavras, a "metodologia" se baseia no seguinte princípio:

"Ninguém educa ninguém, ninguém se educa sozinho, as pessoas se educam entre si, através da atuação firme de uma organização coletiva sobre elas.
Ou seja, num processo de EP (Educação Popular) que pretenda abarcar a totalidade da pessoa, onde o objetivo principal seja transformar comportamentos pessoais para capacitar sujeitos de mudanças sociais, não é possível ficar no apelo à consciência individual, acreditando que cada pessoa vai mudando por determinação de sua vontade individual. Este tem sido o grande equívoco das propostas idealistas de 'conscientização popular'.

É mais fácil o todo mudar a parte que a parte mudar o todo. Num processo pedagógico isto quer dizer que precisamos criar as condições para o fortalecimento da organização coletiva para que ela atue ou faça pressão sobre o comportamento de cada pessoa.” (FUNDEP, 1994: 56).

O Sistema Cooperativista dos Assentados sintetiza atualmente o conhecimento desenvolvido pelo MST durante sua trajetória. Representa um projeto amadurecido diante dos planos utópicos elaborados pela CPT na fase anterior, apontando para uma concepção de vida coletiva um tanto diferente daquela fundamentada na interpretação apenas teológica.

O MST enxerga nas Cooperativas de Produção o instrumento adequado para transformar de alguma maneira a sociedade. Através desse sistema, tenta-se viabili- zar economicamente os assentamentos, permitindo aos assentados realizarem suas expectativas de melhoria na qualidade de vida, ao mesmo tempo em que o próprio sistema cria as situações pedagógicas que vão levando à construção de um novo cotidiano e, em conseqüência, de uma nova mentalidade.

A mentalidade artesanal camponesa que estrutura a produção de subsistência, segundo o MST, é um empecilho que precisa ser superado de qualquer maneira, dado que emperra qualquer tentativa de transformação, além de inviabilizar economicamente os assentamentos e comprometer as lutas pela reforma agrária. Para tanto é preciso que os assentados integrem-se nas regras do mercado capitalista, sabendo produzir com eficiência e lucratividade. A prática tem mostrado que isoladamente é muito difícil que cada assentado consiga adquirir os meios para competir. É mais fácil quando todos se juntam: este tem sido o principal argumento para convencer os assentados a superar a tradição que os leva ao isolamento.

Nesse sentido, o projeto do SCA vem carregado de um senso pragmático, cujo primeiro objetivo aponta sempre para a demonstração aos assentados de que há alternativas reais de produção e gestão da terra que são mais van-

- ${ }^{10}$ Os documentos do Movimento fazem severa restrição ao exercício individual do poder, que consi-

- dera o "presidencialismo" uma forma de gestão não democrática. Cf. Movimento. 
tajosas que aquela escudada em seu modo de vida tradicional, inclusive porque o SCA, através da divisão do trabalho possibilitado pela cooperação de todos, leva a um aumento da produtividade que permite um maior tempo livre para seus associados.

Em relação aos antigos modelos coletivistas elaborados pela CPT, o SCA apresenta pelo menos mais duas diferenças salientes. A primeira delas refere-se à tolerância que os adeptos do novo sistema devem ter com relação aos que optam pelo modo de produção tradicional. Apesar de considerar a produção de subsistência e do modo de vida camponês como fatores que "puxam para trás”, diz o Movimento (Cadernos de Formação, no. 20:18) ser preciso entender que "a grande massa que trabalha individualmente (...) se apóia nas origens históricas e culturais do trabalho isolado". E embora esta forma de produção "pertença ao passado", a adesão ao SCA deve acontecer voluntariamente, por livre escolha de quem quiser participar. Isso não significa porém, que os militantes não possam cercar e usar todas as oportunidades para tentar persuadir, conscientizando as pessoas sobre as vantagens da produção coletiva.

Em segundo lugar, por meio das diversas experiências de coleproblemas decorrentes desse sistema, em especial o da distribuivem buscando maneiras cada vez mais eficientes de responder aos ção do produto do trabalho, que levou à falência a maioria das tentativas de coletivização promovidas pela CPT. Pensa-se muito em formas de premiar o esforço individual, valorizando a qualidade do trabalho realizado, de maneira que as pessoas recebam a parte que lhes cabe segundo seu mérito. É o contrário da distribuição "fraterna", onde todos recebiam o mesmo tanto, independentemente do tempo de trabalho dedicado à coletividade. É desnecessário acrescentar a intensidade dos conflitos causados nos assentamentos por causa disso. Muito embora não se tenha ainda conseguido uma fórmula definitiva de distribuição, o MST sabe que "somente adotando-se mecanismos que permitam medir efetivamente a produtividade física do trabalho é que se conseguirá avançar” (op. cit.:21).

Enfim, é por aceitar que o desafio é "construir o novo ainda dentro do velho, apesar de todas as contradições" (ibidem:51), que o MST representa algo inovador em meio aos projetos já formulados na histórica luta pela terra no Brasil. Sem esconder, persegue um socialismo que não se restringe ao modelo religioso católico, tampouco se enquadra nos modelos racionalistas há tanto tempo cultivados. Resta saber se as relações propostas conseguirão ser materializadas numa prática transformadora. Isto é, se a metodologia adotada possui a necessária coerência entre o discurso e a ação que permita a real alteração dos papéis e a simultâ- nea ressocialização das pessoas, tal como planejado pelo Movimento.

E é nesse sentido que o projeto elaborado pelo MST constitui-se numa espécie de "laboratório" para os cientistas sociais, à medida que não se limita a cultivar um ideal de sociedade lançado para longe, mas preconiza as formas e o método para alcançá-lo. A análise acerca do desenrolar da prática do projeto levado adiante pelo Movimento pode ajudar a encontrar respostas a questões importantes que não tem sido explicadas convincentemente pela reflexão restrita à teoria. Questões do tipo: é possível que um grupo de pessoas consiga controlar sua convivência traçando para si regras e valores racionalmente orientados, tal como o proposto pela teoria do contrato social? Na hipótese de haver algum acerto nisso, esta consciência bastaria para substituir outros elementos importantes na configuração do cotidiano, como a memória, a tradição, os valores, enfim, tudo aquilo de imperceptível, de "inconsciente" e "irracional", que se sintetiza na identidade de cada um, provocando a criação de uma nova identidade por intermédio da razão? Se isso acontecer, quais são as chances de sobrevivência e reprodução das práticas sociais e dessa nova identidade, de um modo de vida "artificialmente" construído por um grupo de pessoas envolvido por um cotidiano baseado em relações e valores tão diferentes? 
MOVIMENTO DOS TRABALHADORES RURAIS SEM TER-

Portanto, isso significa que, mesmo não se concretizando efetivamente as transformações que propõe o Movimento, a trajetória dos seus projetos de intervenção e os resultados obtidos por si sós podem fornecer pistas valiosas à compreensão de algo que é ainda muito obscuro, que há tanto tempo é pensado, mas ainda não foi suficientemente respondido. Trata-se do esclarecimento sobre as contingências da construção do novo, da subjetividade histórica, o que se desdobra aqui em duas últimas perguntas, que como as outras ficam sem resposta: se de fato este mundo de relações materiais e conceituais em que vivemos é uma construção nossa, mesmo que queiramos, porque é tão difícil modificá-lo? Temos de fato tanto controle racional sobre nós e as circunstâncias que criamos quanto acreditamos ou gostaríamos de ter?

\section{Referências Bibliográficas}

COMISSÃO PASTORAL DA TER-

RA. Conquistar a terra, reconstruir a vida. CPT Dez anos de caminhada. Petrópolis: Vozes, 1985.

ESTERCI, N. (Org.). Coletivismo e cooperação no campo. Questões sobre a prática da Igreja Popular no Brasil. Rio de Janeiro: Marco Zero, 1984.

EVERS, T. Identidade: a face oculta dos novos movimentos sociais. Novos Estudos - CEBRAP, $\mathrm{n}^{\circ}$ 4, abril de 1984.
FERNANDES, F. (Org.) Marx/Engels - História. $2^{\mathrm{a}}$ ed. São Paulo: Ática, 1985.

BETTO, Frei. Comunidades Eclesiais de Base e Educação Popular. In FLEURI, R.M. (Org.) Movimento popular, política e religião. São Paulo: Loyola, 1985, P. 27:40.

FREIRE, P. Ação cultural para a liberdade e outros escritos. $2^{\mathrm{a}} \mathrm{ed}$. Rio de Janeiro: Paz e Terra, 1977.

.Pedagogia do Oprimido. $16^{\mathrm{a}}$ ed. Rio de Janeiro: Paz e Terra, 1986.

FUNDEP. Coragem de Educar. Uma proposta de Educação Popular para o meio rural. Petrópolis: Vozes, 1994.

KRISHKE, Paulo. As CEBs na "Abertura": mediações entre a reforma da Igreja e a transformação da sociedade. In KRISHKE, P., MAINWARING, S. (Orgs.). A Igreja nas bases em tempo de transição. São Paulo: L \& PM - CEDEC, 1986.

MACEDO, C. C. Tempo de Gênesis. O povo das Comunidades Eclesiais de Base. São Paulo: Brasiliense, 1986.

MARTINS, J. S. Expropriação e Violência. A questão política no campo. $3^{\text {a }}$ ed. São Paulo: Hucitec, 1991.

Caminhada no chão da noite. Emancipação política e libertação nos movimentos sociais no campo. São Paulo: Hucitec, 1989.
RA. Caderno de Educação n ${ }^{\circ} 3$. Alfabetização de jovens e adultos. s.l., s.n., 1994. Caderno de Formação $\mathrm{n}^{\circ} 2$ - Setor de Educação. Como fazer a escola que queremos. s.l., s.n.,. 1991.

Caderno de Formação $\mathrm{n}^{\circ}$ 20. A cooperação agrícola nos assentamentos. s.l., s.n., 1993.

Cartilha $\mathrm{n}^{\circ}$ 2: Vamos organizar a base do MST. s.n.t.

PAIVA, V. (Org.). Igreja e Questão Agrária. São Paulo: Loyola, 1985.

PELOSO, R. A força que anima os militantes. São Paulo: MST, 1994.

SILVA, J. G. A modernidade dolorosa. Estrutura agrária, fronteira agrícola e trabalhadores rurais no Brasil. Rio de Janeiro: Zahar, 1982. 